\title{
LA MODERNIDAD EN JUEGO: EL DEPORTE Y LAS REVISTAS ILUSTRADAS EN EL PERÚ 1885-1930
}

\author{
POR \\ DAvid WoOD \\ University of Sheffield
}

¿Qué modernidad deseamos? Esta pregunta, que constituye el título de una colección de ensayos publicada bajo la coordinación de David Sobrevilla y Pedro Belaúnde en 1994, y que lleva como sub-título "El conflicto entre nuestra tradición y lo nuevo", nos revela que la relación que tenía el Perú con la modernidad no se llegaba a definir a finales del siglo XX. Una serie de respuestas se siguen produciendo en las primeras décadas del siglo XXI desde campos diversos, tales como la filosofía, la antropología, la literatura y las artes visuales, pero el propósito de este ensayo es explorar las formas en que la convergencia de los deportes y las revistas ilustradas a finales del siglo XIX y comienzos del XX contribuyó a establecer las bases de una temprana experiencia de la modernidad en el país. El ilustre historiador Jorge Basadre había comentado ya en 1947 que el auge de los deportes en el Perú durante las primeras décadas del siglo XX no era un fenómeno banal sino que se trataba de un índice de la modernidad urbana (253-54). Sin embargo, a pesar de registrar algunos hechos notables con respecto al desarrollo de los deportes en su monumental Historia del Perú, Basadre no elabora las implicancias de la cada vez mayor presencia de actividades como el ciclismo, el atletismo y el fútbol en la vida cotidiana de los peruanos. El presente trabajo también constituye un aporte a nuestro entendimiento de las interacciones entre deportes y cultura visual en el Perú y, por extensión, otros países de América Latina.

Conforme a una apreciación de la modernidad como "la experiencia de vivir con cambios rápidos, extensos y continuos" (Hall 278), que puede constituir un importante elemento de ruptura consciente con la tradición, nuestras indagaciones van a enfocar lo que Dussel identifica como la segunda etapa de la modernidad (470), la cual coincide con la revolución industrial y la expansión de la influencia de Gran Bretaña y Francia como poderes mundiales en relevo de España y Portugal. Esta influencia se hizo sentir en el Perú, como en el resto de América Latina, sobre todo en la segunda mitad del siglo XIX y las primeras décadas del siglo XX, periodo que coincidió precisamente con la llegada de los deportes y de las revistas ilustradas que serán el punto de análisis de nuestro trabajo. En su estudio de los años 1920 y 1930 en Buenos Aires, Beatriz Sarlo 
identifica lo que denomina una "modernidad periférica", lo cual no desmiente que la modernidad se asocie con las grandes metrópolis, sino que esa capital latinoamericana en vez de constituir un centro moderno fue más bien un margen desde el que se organizó un discurso particular. Tales observaciones, que evidencian las tensiones entre centro y periferia que se experimentaban por parte de los intelectuales locales, pueden aplicarse asimismo al Perú del mismo periodo, donde las ideas y prácticas europeas -sobre todo las que procedían de Gran Bretaña y Francia- se adaptaban y se aplicaban a la realidad del país, especialmente a la de Lima. Al comentar el impacto de estos cambios en el Perú después de regresar de Europa, José Carlos Mariátegui opinó en un texto publicado en El Mundial que "el hombre de las urbes vive de prisa, la velocidad es una invención urbana, una cosa moderna" (1924), afirmación que hace eco con la observación de Sarlo, de nuevo con respecto al Buenos Aires de los 1920, que "la experiencia de la velocidad y de la luz modelan un nuevo elenco de imágenes y percepciones" (16). Lo que no contemplan ni Mariátegui ni Sarlo es la manera en que los deportes, y su representación fotográfica en las revistas de la época, constituyen una forma privilegiada de combinar estos elementos centrales de velocidad y luz en la creación de una modernidad periférica.

Los orígenes de la prensa ilustrada se encuentran en Gran Bretaña, donde The Penny Magazine (1832-1844) alcanzó un tiraje de 200,000 ejemplares, dirigiéndose a un público masivo con grabados en madera que acompañaban los textos informativos. $L a$ Ilustración Argentina se publicó por primera vez en Buenos Aires en 1853 y en España Museo Universal se hizo popular en 1857 para luego convertirse en La Ilustración Española y Americana que se exportaba a los países de América Latina. En el Perú se considera por lo general que El Perú Ilustrado (1887-1892) es la primera revista ilustrada nacional (Tauzin 133), pero para Gargurevich "la revista pionera de la ilustración periodística [es] El Correo del Perú" ("Del grabado" 138-39), cuya primera edición salió el 16 de setiembre de 1871. Cualquiera que sea el caso, lo que hay que destacar en el contexto del presente estudio es que las primeras revistas ilustradas en el Perú participaban de manera explícita en un circuito internacional en el que circulaban tanto imágenes (que se podían alquilar de fuentes europeas) como ideas. Una de las primeras reseñas de El Perú Ilustrado, publicada en La Opinión Nacional del 15 de junio de 1887 , lo compara de forma favorable con las revistas ilustradas que se importaban, concluyendo que "nuestra culta sociedad podrá enorgullecerse de poseer un periódico ilustrado a la altura de los mejores que aquí nos llegan". Al mismo tiempo, títulos como La Ilustración Americana (Lima, 1890-1891; bimensual) y su sucesor La Ilustración Sud Americana (Lima, 1891-1892) dan testimonio de una visión -literalmente- que se hacía sentir a nivel continental.

Según Gargurevich, el uso de ilustraciones e imágenes llega al periodismo peruano "con retraso en comparación con el de otros países incluso de Sudamérica" ("Del grabado" 133), confirmando de nuevo el carácter periférico de la modernidad en el

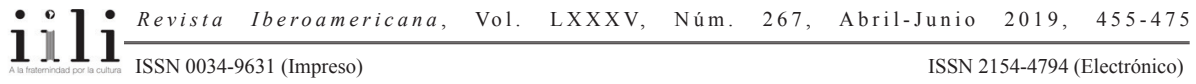


país, pero al pasar al mundo hispano las revistas ilustradas gozan de una marcada ventaja frente a sus equivalentes en el mundo anglo-parlante. Al servirse en muchos casos de títulos como El Perú Ilustrado, La Ilustración Sud Americana, o incluso de subtítulos como en el caso de Variedades. Revista Semanal Ilustrada, las variantes de "ilustrar" introducen una deliciosa ambigüedad que logra plasmar el aspecto visual con el propósito conceptual, el uso de imágenes con la promoción de la modernidad como ideología, donde la ciencia y la razón de la Ilustración europea remplazan la tradición y la fe religiosa como supuestas fuerzas motrices de la nueva sociedad nacional. Las revistas ilustradas pueden, entonces, considerarse simultáneamente como causa y efecto de la modernidad: eran una causa de nuevas formas de pensar por los textos que exploraban temas científicos, por el uso de imágenes para construir una idea del Perú como Nación-estado que formaba parte del mundo occidental, y por la presencia de avisos que confirmaban su lugar en el mercado capitalista internacional. Al mismo tiempo, eran un efecto de la modernidad en las nuevas técnicas que permitían la reproducción de grabados y luego fotografías, en la llegada de los Estados Unidos a comienzos del siglo XX de grandes máquinas capaces de imprimir miles de ejemplares en cuestión de horas (Gargurevich, Prensa, radio y TV 83), y en el creciente público que sabía leer gracias a la educación pública que en 1905 se hizo gratuita y obligatoria (Núñez 120). También cabe mencionar aquí que el nuevo plan de educación pública incluía por primera vez la educación física (Muñoz Cabrejo 207), y que las revistas ilustradas circulaban en un ámbito donde la modernidad visual era una experiencia cotidiana para los limeños, sobre todo mediante los numerosos proyectos de construcción que se comentarán abajo.

La fotografía, el otro ingrediente crucial para el éxito de las revistas ilustradas a comienzos del siglo XX, llevaba ya casi medio siglo en el Perú, desde que Eugène Courret (de origen francés) instaló en Lima su estudio fotográfico en 1856. La década de los años sesenta del siglo XIX fue la época de oro del estudio fotográfico en el Perú, pero la reproducción de fotografías en los periódicos y revistas resultó ser muy complicada por una serie de razones técnicas: en 1871 El Correo del Perú usó “el método de sensibilizar tacos de madera para estampar allí la fotografía que era luego grabado por un experto" (Gargurevich, "Del grabado" 138), pero las dificultades en llevar a cabo el proceso se hicieron sentir en el hecho de que El Correo del Perú llevó como subtítulo "periódico semanal con ilustraciones mensuales". En la década de los ochenta, el empresario norteamericano Peter Bacigalupi (el fundador de El Perú Ilustrado) importó las pequeñas cámaras Kodak al Perú como otra prueba del buen funcionamiento de los circuitos de la modernidad, y en los años posteriores se comenzó a construir un imaginario nacional con las fotografías. Para dar constancia del supuesto uso en todo el territorio nacional de estas nuevas tecnologías El Perú Ilustrado pidió en su sexto número (18 de junio de 1887,12$)$ fotos de sus lectores para contribuir a su misión de ofrecer una visión del Perú como país moderno: “A nuestros lectores del

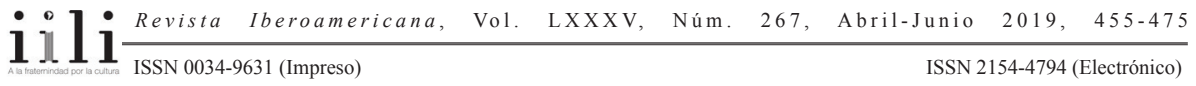


interior de la República. Suplicamos nos manden fotografías y dibujos de su localidad que puedan ser de interés general. Por las que aceptemos y publiquemos pagaremos un buen precio". En julio de 1888 la afición a la fotografía ya era suficiente como para fundarse Foto Club Lima, institución que en 1889 contaba con 65 socios y órgano propio (Revista Literaria y Cientifica), cuyo primer texto editorial marca el momento: "Al fin tenemos luz, ese fluido solo comparable al pensamiento, que esclarece y vivifica", para concluir con la declaración de su lema: "la ilustración mata la guerra", estableciendo así una relación estrecha entre luz e ilustración (tanto visual como ideológica) en la práctica de la fotografía en el Perú.

A pocos años del final catastrófico de la Guerra del Pacífico(1879-1883), que provocó un profundo cuestionamiento de las tradicionales estructuras de poder en el Perú, la preferencia por las ideas modernas como futuro para el país se entiende perfectamente, mientras que el énfasis en la luz como elemento imprescindible combina de forma feliz el sentido de la Ilustración con la clave de la fotografía (literalmente escribir o pintar con luz), al mismo tiempo que nos recuerda la importancia que presta Sarlo a la luz (y a la velocidad, que también es propiedad de la fotografía) en la formación de un nuevo imaginario moderno (Una modernidad periférica 16). A pesar del entusiasmo de los aficionados de Foto Club Lima, y la presencia difundida de la cámara fotográfica para uso personal, la producción de fotograbados en la prensa peruana solo se llegó a realizar después de la instalación en el Perú de Charles Southwell, cuyos conocimientos de las técnicas necesarias facilitaron la publicación de un gran fotograbado en El Comercio del 31 de julio de 1898. Por razones de limitaciones técnicas, tales fotograbados representaban figuras estáticas ya que no había acceso a las innovaciones que permitirían captar con nitidez figuras en movimiento rápido. Las diferentes etapas de la fotografía han jugado un papel imprescindible en el desarrollo de las tecnologías y técnicas necesarias a la presencia del deporte en las revistas ilustradas en el Perú, pero también han sido importantes las asociaciones con Europa del norte y los Estados Unidos como los dos ejes de la modernidad en el país. Desde el francés Courret y la introducción de la primera fotografía hasta el inglés Southwell y la llegada de las técnicas del fotograbado, pasando por Bacigalupi (inmigrante de EEUU de descendencia italiana además de fundador de El Perú Ilustrado) y las máquinas Kodak que hicieron posible la fotografía para aficionados, la importación material en esta época iba de la mano con la importación de ideas, sobre todo la noción de la modernidad.

El Perú Ilustrado ha gozado de más atención crítica que cualquier otra revista peruana, pero un aspecto que no se ha considerado hasta ahora es su contribución a la temprana difusión del deporte en el país. En parte El Perú Ilustrado sirvió para anunciar la llegada de nuevos aparatos tecnológicos y productos de consumo (máquinas de coser Davis, lámparas de kerosene Hitchcock, cervezas británicas y alemanas, confitería suiza) que se ofrecían al mercado peruano mediante las varias empresas de Bacigalupi, confirmando así la participación del país (o al menos ciertos sectores de él) en el mercado

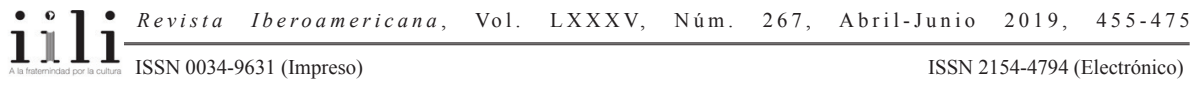


capitalista internacional. Al mismo tiempo cumplió un papel importante en la (re) construcción pos-Guerra del Pacífico de un imaginario nacional con sus ilustraciones (fotos y grabados) de lugares, personas ilustres, tipos populares y fauna del país, así como la promoción de ideas y prácticas de Europa y Estados Unidos declaradas "modernas". La importancia de Inglaterra se hizo sentir con particular fuerza en el número 7 ( 25 de junio de 1887), que llevó en su portada un grabado de la reina Victoria "con motivo del quincuagésimo aniversario de su exaltación al trono. Accediendo, por otra parte, a la solicitud de muchos distinguidos miembros de esa importante colonia consignamos, escritos en su propio idioma, ligeros apuntes biográficos de su augusta soberana". En efecto, las páginas seis y siete se dedicaron casi en su totalidad a una celebración -en inglés- de algunos episodios notables de su reinado. Esta fuerte influencia británica se hizo sentir en el deporte en el Perú inicialmente a través de las carreras de caballos, identificadas por Basadre como el primer deporte de origen inglés en introducirse al país (Historia vol. X 65), y El Perú Ilustrado se sirvió de ellas en varias oportunidades para evocar la supuesta modernidad del mundo anglo-sajón. En el número 25 de la revista, del sábado 29 de octubre de 1887, la contra-portada (16) llevó el grabado que se encuentra a continuación.

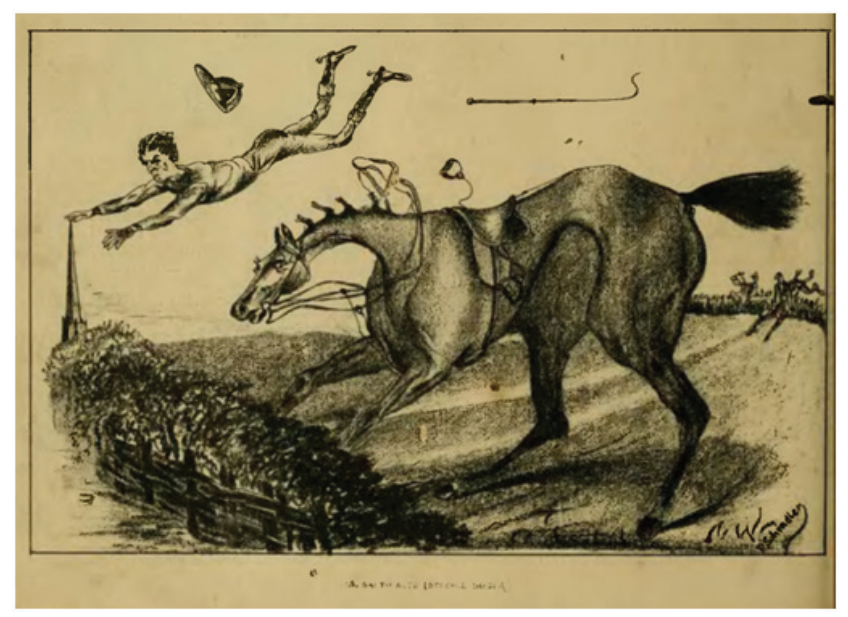

Se explica en la sección "Nuestros grabados" del mismo número, donde se ofrecen comentarios sobre las imágenes que figuran, que se trata de "la vista de un salto alto (Steeple Chaser), pequeño cuadrito que no dudamos será muy del agrado a los aficionados de este género de ejercicios" (2). El cuadro se inspiró sin duda en las carreras de caballos en Gran Bretaña: además del uso del inglés entre paréntesis, tanto el paisaje como la iglesia con torre alta (el steeple del título, que servía de punto de partida y llegada en las carreras) son una representación del país que había figurado

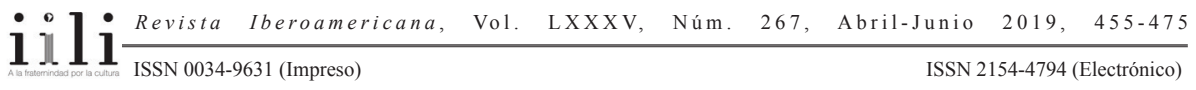


con el aniversario de la reina Victoria. Asimismo, las prácticas que se celebran en el cuadro y en el texto tienen ambas sus orígenes en Gran Bretaña: el Steeplechase se estableció en las primeras décadas del siglo XIX, cuando el salto alto también se comenzó a practicar de forma competitiva.

El Correo del Perú, que dejó de publicarse antes de la Guerra del Pacífico, había hecho uso de grabados que se importaban -alquilados- de Europa y que circulaban en América del Sur (Gargurevich, "Del grabado" 139), pero El Perú Ilustrado empleó a sus propios grabadores, como el conocido Evaristo San Cristoval. Por su temática, podría parecer que en el caso de "Salto Alto (Steeple Chaser)" se trata de una imagen importada, pero como se puede confirmar de la firma es un trabajo del "joven Don Pablo Schindler, de nacionalidad alemana, especialmente contratado para el servicio de El Perú Ilustrado, y muy digno de recomendación, por ser conocedor del arte litográfico en todos sus recursos y últimos adelantos" (2 de julio de 1887, énfasis mío). En números posteriores, se describió un poco el proceso litográfico mediante el cual Schindler producía sus retratos, basándose en fotografías de Courret y de Bacigalupi (28 de enero de 1888, 15), y cómo empleaba "un procedimiento enteramente nuevo en el país" (11 de febrero de 1888, 2, énfasis mío). Lo que nos revela "Salto Alto (Steeple Chaser)", entonces, es la forma en que una ilustración puede combinar una práctica deportiva asociada con la Gran Bretaña decimonónica con técnicas que implican la participación del Perú en la modernidad, tanto por el mercado capitalista internacional como el concepto occidental del tiempo como proceso linear que lleva al "desarrollo".

En otra ilustración de Schindler para El Perú Ilustrado, publicada en el número 31 (10 de diciembre de 1887, 9), se vuelve a enfocar la carrera de caballos.

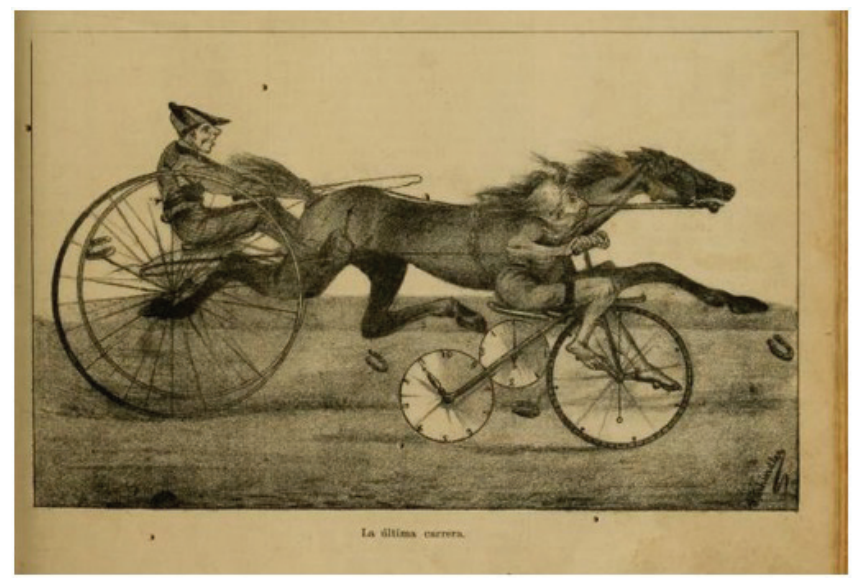

Sin embargo, en esta oportunidad la alusión a Gran Bretaña no queda tan clara, ya que esta forma de carrera de caballos también era muy popular en los Estados

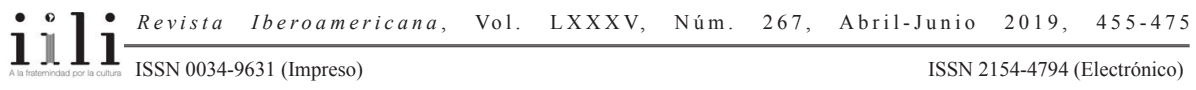


Unidos (Temple 13-16). Es muy posible que este grabado se haya inspirado en "A Chance Brush-Bicycle Against Buck-Board", grabado de A.S. Daggy que se publicó en Harper's Weekly en agosto de 1887, pero las carreras entre caballos y bicicletas también se hicieron famosas en Gran Bretaña en 1887, cuando el espectáculo de "Buffalo Bill's Wild West" llegó para formar parte de los festejos en el aniversario de la reina Victoria. Cabe mencionar que por esas fechas la bicicleta solo se conocía en el Perú mediante representaciones en revistas, ya que los primeros ejemplos llegaron al Perú recién en 1890, traídas desde Europa por jóvenes de la aristocracia (Basadre, Historia vol. XVII 163; Muñoz Cabrejo 215). Cualquiera que sea la inspiración para el grabado de Schindler, la combinación de la "última" del título con el uso de ruedas de bicicleta que parecen relojes sugiere de nuevo la participación del Perú en un tiempo deportivo que implica progreso y avance, además de testimoniar el flujo de ideas e imágenes en un circuito internacional-occidental, condición imprescindible de la modernidad.

Los caballos, por supuesto, no llegaron al Perú con los británicos, sino con los primeros conquistadores, $\mathrm{y}$ se asociaron desde el periodo colonial con las corridas de toros, actividad que no gozaba de las mismas simpatías entre los que promulgaban ideas modernas a través de El Perú Ilustrado. El número 40, del 11 de febrero de 1888, llevó una ilustración taurina en la contra-portada, la cual se describió en la sección "Nuestros grabados" de la siguiente manera: "En la página 16 publicamos una nueva composición taurina de Garay, que cada día va probando más su amor al arte, no de Pepe Hillo, sino del dibujo". Según el texto que acompaña el cuadro representa una cogida en la corrida del 22 de enero, donde el torero voló por el aire sobre la espalda del toro, ofreciendo así una visión muy poco positiva de las corridas como elemento de la tradición española. En el número siguiente (18 de febrero de 1888) también figura un grabado del toreo en la contra-portada, el cual se puede apreciar abajo con el título "El salto a la garrocha".

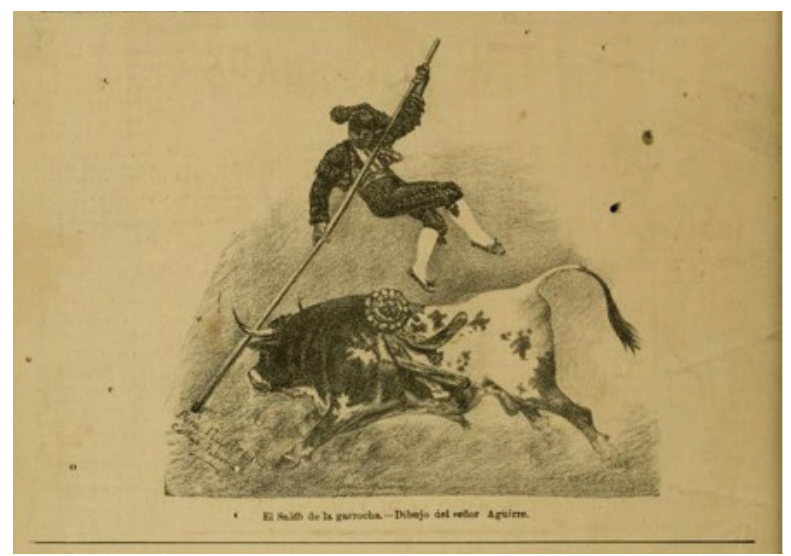

\begin{tabular}{l}
-111 \\
\hline ISSN 0034-9631 (Impreso)
\end{tabular} 
El uso del salto de la garrocha como punto de referencia va de la mano con el salto alto que se comentó arriba. Como práctica tiene una larga historia en las zonas pantanosas del este de Inglaterra (y en Holanda) para pasar canales donde no había puente, pero el primer registro de una competencia para pasar una barra vertical es de Ulverston Football and Cricket Club (Cumbria, Inglaterra) en 1843. Este grabado cumple entonces varios propósitos: demuestra la forma en que el uso de un nuevo ejercicio atlético británico podría evitar una cogida del tipo que se había representado en el número anterior, y la organización visual del toro y el que practica el salto de la garrocha sugiere la superioridad del elemento moderno (británico) sobre el elemento tradicional (español). También cabe señalar que los grabados de los toros son de Garay y Aguirre, lo cual nos indica que estas ilustraciones que combinan deporte y modernidad no son obra solamente de Schindler, sino que obedecen una ideología que se hace sentir de forma más amplia en la revista.

Además de estos grabados, hay varios textos en El Perú Ilustrado donde surge el atletismo, como por ejemplo el "Cuento alegre" que se publicó en el número 14 (13 de agosto de 1887) y que cuenta así:

- ¿Por qué le da usted una paliza, todas las mañanas, a su esposa?

-Señor, el médico me lo ha recomendado, hace tiempo.

-¡Cómo así!

-Me dijo que la procurara un buen ejercicio, todos los días en ayunas, a fin de que almorzara con apetito; y como de cada palo que le arrimo salta tres varas del suelo y suda la gota gorda, he preferido este medio al de llevarla de paseo por las calles, donde puede coger un constipado. (11)

Las acciones del esposo tienen muy poco de ilustrado, pero el humor se deriva no de la sugerencia del médico de que las señoras deban tomar ejercicio, ni del salto alto doméstico que realiza la esposa, sino de la falta de comprensión que muestra el esposo frente a las ideas científicas con respecto al deporte moderno, así como sus ideas anticuadas. También la figura del atleta aparece en un poema de Juan de Arona (seudónimo de Pedro Paz Soldán y Unanue), publicado en el número 25 (sábado 29 de octubre de 1887, 3). Bajo el título “Despedida en Buenos Aires. Al Sr. Don José M Samper" el célebre diplomático y autor del Diccionario de peruanismos recuerda los tiempos que pasó en Lima con Samper, a quien compara con un "campeón y atleta", lo cual hace rima dos versos después con "aliento del poeta”. Esto constituye quizás el primer ejemplo de la presencia del deporte en las letras peruanas, y expresa al mismo tiempo la visión modernizadora tanto de Arona como del político colombiano.

En los ejemplos que se han comentado arriba, las referencias del deporte son más o menos implícitas, pero el artículo "Juegos atléticos" del número 30 (3 de diciembre de 1887) se encarga de promulgar los beneficios de la práctica del deporte de forma

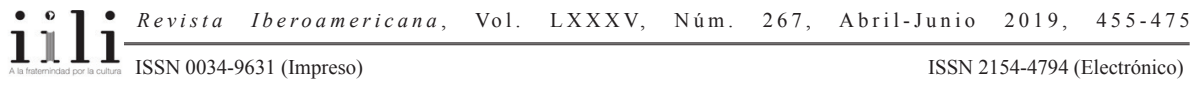


explícita y clara. Con motivo de unos "juegos atléticos que tendrán lugar en la Cancha Meiggs el 8 del presente, organizados por el Club Cricket y Tennis de Santa Sofia" se lamenta la falta de este tipo de actividad entre los jóvenes peruanos: "Pocos son en el Perú los colegios (hablamos de los nacionales) que cuenten con un regular gimnasio; la totalidad, no tiene ni los aparatos más rudimentarios" (6). Esta situación se contrasta con lo que pasa en el mundo angloparlante: "En otros lugares y especialmente en Inglaterra y E.U. de Norte América, países prácticos y progresistas, sucede todo lo contrario. Desde tierno al niño se le hace ejercitar sus fuerzas; que corra, que salte, que suba montañas, que luche con su misma debilidad; que se acostumbre a soportar fatigas y privaciones; en fin, que se haga hombre" (6). Lo que hay que destacar en este texto es el hecho de que sean Inglaterra y los Estados Unidos los países que se toman como modelos en la revista, ya que son los que se encuentran en la vanguardia del mercado capitalista que forma precisamente un elemento importante de la modernidad -y eran además los proveedores de la mayoría de los bienes de consumo que se ofrecían a través de las páginas de El Perú Ilustrado-. Al mismo tiempo, la presencia de la noción del progreso ubica al Perú dentro de una conceptualización del tiempo lineal concebido desde un centro occidental, otro factor fundamental en cuanto a participación en la modernidad. Al seguir la referencia a estos países con una consideración de la forma en que un niño se hace hombre el autor se sirve de un solo discurso de crecimiento y desarrollo tanto para el uno como el otro: mejorar la capacidad física de los peruanos irá de la mano con mejorar el país, clara expresión del positivismo y progreso que caracterizaban al pensamiento ilustrado y modernizador.

La necesidad de prestar atención a la condición física de los peruanos se había hecho evidente con la debacle de la Guerra del Pacífico, y la inclusión de las sociedades de tiro como ejemplo de una "útil institución" (El Perú Ilustrado, 1887, 6) revela que el deseo de estimular la participación en actividades deportivas obedecía, en parte por lo menos, a un afán por defender el país en posibles conflictos con países vecinos.

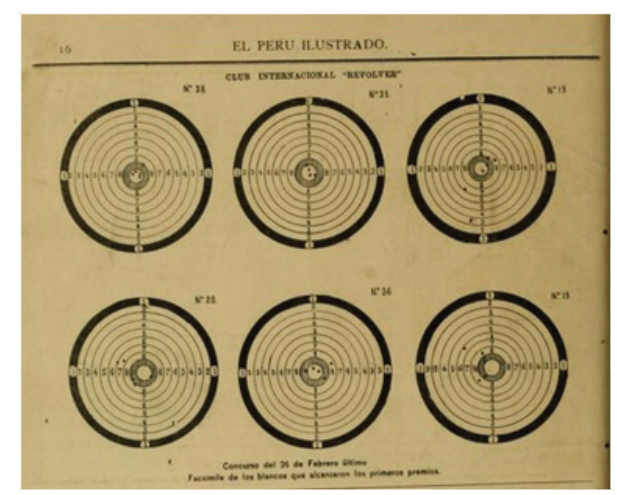

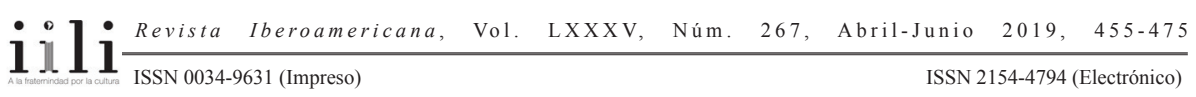


Esto explicaría la reproducción en la contra-portada del número 44 (10 de marzo de 1888) de los blancos de una competencia de tiro realizada por el Club Revólver en febrero de ese año.

Poder visualizar los resultados de este concurso de tiro ofrece una familiaridad con la práctica y un estímulo a igualar tan buenos resultados, que podrían asegurar al público lector de la eficacia de los tiradores peruanos. Para El Perú Ilustrado, al participar en tales actividades atléticas:

[...] vienen despertando entre nosotros la inclinación a esos juegos varoniles y de desear sería que los Municipios, los maestros y los padres de familia concedieran a esos ejercicios toda la gran importancia que tienen.

En ellos, á la vez que se educa y se fortalece el cuerpo, el espíritu tiene esa espansión [sic] de que carece en la estrechéz de los salones. (3 diciembre de 1887, 7)

La alusión a la célebre frase de Juvenal "mens sana in corpore sano” para los lectores de la revista es otra muestra de una conexión con las ideas de la Ilustración en la que se inspira la modernidad de la época, y John Locke, uno de los grandes pensadores de la Ilustración, también empleó la frase en su tratado sobre la educación. El que la frase gozara de cierta difusión y aceptación también en otras partes de América Latina se observa por el hecho de que la tomaran como lema instituciones como el Club de Gimnasia y Esgrima La Plata (fundado en 1887) y el Internado Nacional Barros Arana en Chile (planeado en 1887). El artículo concluye animando a los lectores a que asistan al evento en el Club Santa Sofía, y "hacemos votos por que nuestra juventud luzca algún día en las calles de Lima la pala del Cricket, en lugar del flexible e inútil bastoncillo dominguero" (7), buscando que la tradición hispánica del paseo del domingo después de asistir a la misa católica se remplace por la práctica de un deporte importado por los ingleses. Sin embargo, el número que se publicó después del evento (17 de diciembre de 1887) lleva un texto breve que confirma que "El jueves 8 se verificaron los anunciados 'Juegos Atléticos' ante una regular concurrencia”, pero concluye que "sentimos muchísimo que la Cancha no hubiese estado más concurrida". Ver en las calles de Lima grupos de jóvenes con palos de cricket sería una aspiración que no se llegaría a realizar, pero la participación masiva en la práctica de otros deportes se produciría en un futuro no muy lejano.

El auge de los deportes y de las revistas ilustradas en el Perú a partir de la década de los años noventa del siglo XIX, al cual contribuye El Perú Ilustrado, se produjo en un momento decisivo en el que el país buscaba una nueva dirección frente a su derrota en la Guerra del Pacífico. Volcar la mirada hacia adentro (el indigenismo) es una de las respuestas a esta crisis, pero también lo es ver en la Europa del norte un modelo ideológico y cultural, y a pesar de las marcadas diferencias de perspectiva las dos partes emplean un discurso parecido, en el que la tarea de modernizar la nación

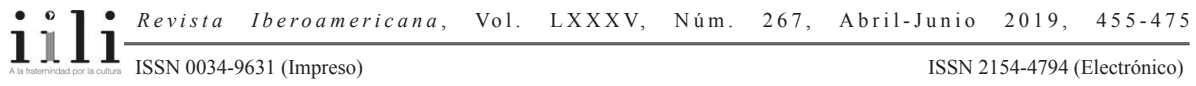


jugaba un papel central. Desde que el Perú obtuvo su independencia de España en 1821 el antiguo poder colonial dejó de constituir el patrón a seguir, y la pérdida de Cuba y Puerto Rico en 1898 marcó otro hito simbólico tanto en América Latina como en la misma España. Por lo tanto, en la reconstrucción de Lima después de que las tropas chilenas saquearan la ciudad en La Guerra del Pacífico - la cual se sumó a la necesidad de expandir la ciudad más allá de sus murallas históricas, derruidas en 1870-el plano de la nueva Lima ya no seguía el histórico formato de cuadrados sino las amplias avenidas parisinas de Haussman. En el plano de la época que se reproduce abajo se puede apreciar la diferencia entre la organización de la ciudad colonial en cuadras compactas al lado del río Rimac (el famoso "damero de Pizarro") y las largas avenidas que se extienden hacia el sur y el oeste de las antiguas murallas de Lima.

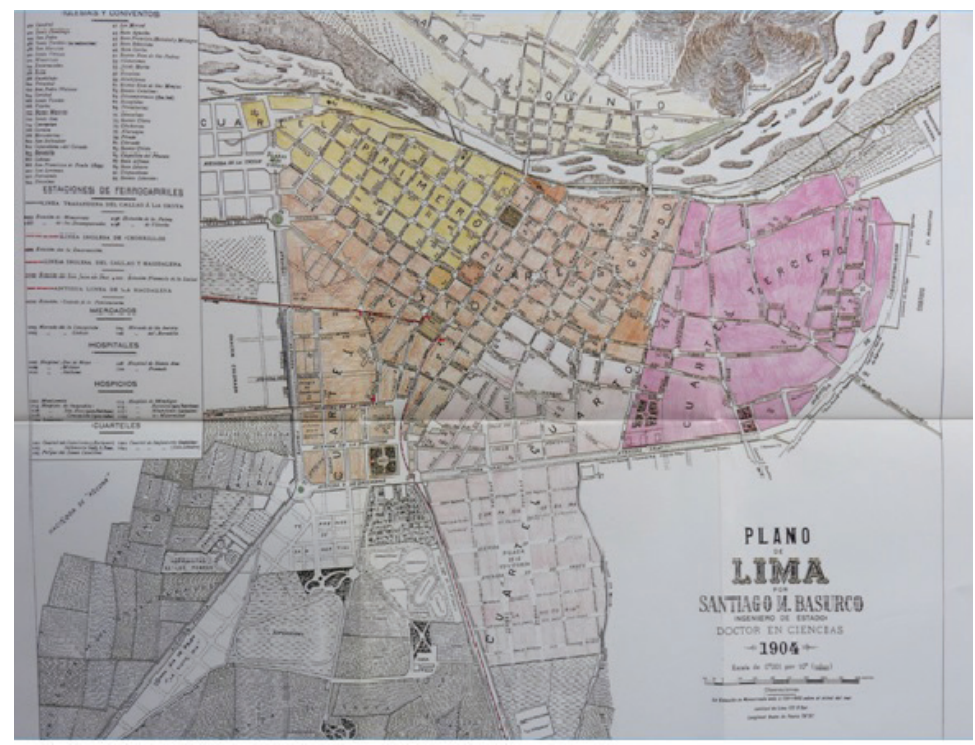

En su análisis de la época, Muñoz Cabrejo concluye que fue durante la presidencia de Nicolás de Piérola (1895-1899) que "la estabilidad política y la bonanza económica obtenidas por el auge de las exportaciones establecieron las bases materiales para la modernización del Estado" (44-45). Uno de los aspectos más visibles de esta modernización fue la infraestructura de la capital, que gozó de la inauguración de la Avenida de la Colmena en 1898, mientras la construcción del Paseo Colón y la Avenida de la Magdalena por ese periodo marcó la apertura de la ciudad hacia nuevos horizontes que se alejaban del centro colonial. La construcción de un monumento a Bolognesi, héroe de la Guerra del Pacífico, significó la emergencia de la ciudad -literalmentede las cenizas de ese conflicto, así como las bases de una nueva identidad nacional

11
11 
elaborada frente al país vecino (ya no España) como su otro más significativo. Además de tales proyectos que llevaban un fuerte valor simbólico, otros tenían fines más bien prácticos, como por ejemplo: el establecimiento de un sistema de canalización de agua y desagüe; el reemplazo del viejo alumbrado público de gas por la energía eléctrica (1902); el funcionamiento del ferrocarril que conectaba Lima con el balneario de Chorrillos (1904); o la inauguración del tranvía eléctrico urbano (1906). En parte estas obras obedecían a la necesidad de responder a la expansión de la ciudad, que se había duplicado en extensión entre 1858 y 1908, y que pasó de tener 120,994 habitantes censados en 1876 a 172,927 en 1908 y 223,807 en 1920 (Muñoz Cabrejo 47), pero también eran fruto de una ideología que tuvo el resultado (si no el propósito) de hacer que la vida diaria de los limeños fuera moderna. Además de una experiencia cotidiana de la modernidad a través de las nuevas tecnologías que se introducían de forma masiva y pública en las revistas ilustradas, las nuevas vías públicas, espacios de ocio y una serie de nuevos edificios públicos (la Casa de Correos y Telégrafos, 1900; el Instituto Nacional de Higiene, 1902; el Teatro Municipal, 1909) constituyeron otra dimensión de la visualización de la ciudad.

Dentro de esta explosión de cambio y proyectos de construcción que remodelaron el aspecto físico y visual de la ciudad, así como las vivencias cotidianas de ella, se insertó el rápido crecimiento de los deportes como práctica popular y masiva. Muñoz Cabrejo da constancia de la fundación entre 1895 y 1925 de una treintena de clubes de fútbol en varios distritos de Lima, así como tres clubes de box y dos de ciclismo (277-82), cada uno de los cuales contaba con acceso a una cancha, velódromo o ring. El boom en los deportes implicaba no solo la participación en una serie de prácticas físicas "europeas" que incorporaban conceptos como la disciplina, la fortaleza y mejorar la raza sino también participación en el mercado internacional que aseguraba la llegada de tecnologías y artículos deportivos.

En el fragmento que se reproduce abajo del mapa de Lima de 1904 se puede apreciar con mayor detalle la zona al suroeste de la ciudad colonial donde el monumento a Bolognesi se construyó en el lugar que había marcado la esquina de las antiguas murallas (indicado por el número 37 en la parte superior izquierda del mapa). También aparecen en el espacio central del mapa leyendas para los nuevos campos donde se practicaban varios deportes: Campo Escolar (x2), Velódromo (estrenado en 1897), [Colegio] Guadalupe, Juego de pelota, Club Cricket y, un poco más hacia el oeste, Hipódromo (inaugurado en 1903).

Lo que queda claro es que la preparación de lo que ahora se podría denominar una ciudad deportiva fue un proyecto importante que se realizó a la par de la construcción de edificios públicos y una nueva infraestructura urbana, la cual se representaba constantemente en las revistas ilustradas de la época. La inauguración en 1898 del primer campo deportivo en los terrenos de la hacienda Santa Beatriz (donde se construyó el velódromo, cancha para practicar fútbol, rugby y cricket) coincidió con el surgimiento

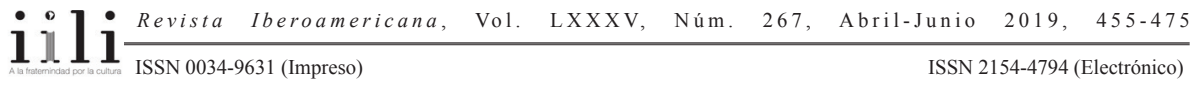




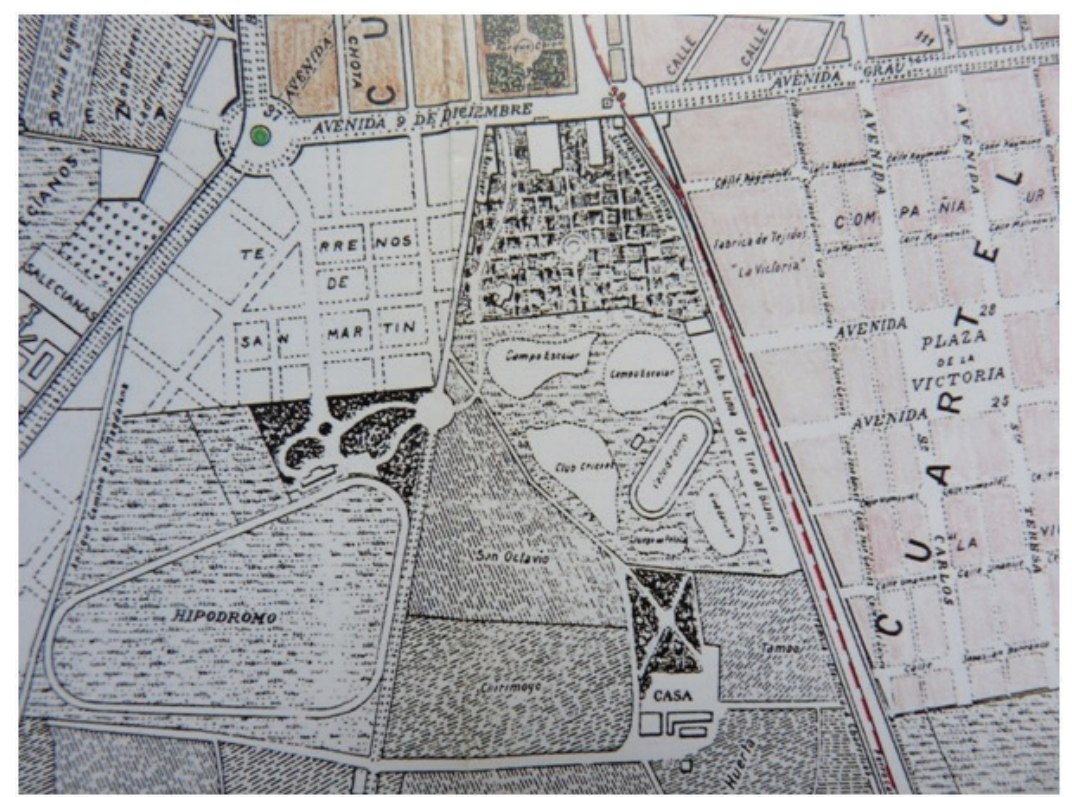

del barrio de la Victoria, descrito por Panfichi como "un barrio moderno producto de la inversión, diseño, y lotización de dos empresas inmobiliarias: Compañía Urbana La Victoria y Compañía Nacional La Cerámica". La presencia de un barrio obrero al lado de los nuevos terrenos deportivos aseguró que los deportes -sobre todo el fútbol- no se restringieran a las élites tradicionales. A inicios del siglo XX, se institucionalizaron en los campos de Santa Beatriz las famosas -y atléticas- Fiestas Escolares que se habían iniciado en 1894 para que se celebraran durante las Fiestas Patrias, organizadas y presididas por los jefes de Estado. Esta visibilidad pública de prácticas deportivas que se asociaban con la modernidad, y con la proyección de una nueva visión del país, alcanzó quizás su culminación simbólica cuando en el día del centenario de la Independencia del Perú se comenzó en los campos de Sta. Beatriz la construcción del Estadio Nacional (de fútbol), obsequio a la nación de la comunidad británica en Lima.

La creación de espacios públicos dedicados a la práctica de los deportes constituyó un elemento importante en la visibilidad de la modernidad como experiencia cotidiana en la Lima de las primeras décadas del siglo XX. Para muchos, su participación se realizaba de forma personal al pasar los nuevos campos deportivos que se construían en un espacio abierto y estratégico para los que se movían más allá de los confines de las antiguas murallas de la ciudad colonial, sobre todo si lo hacían en el ferrocarril o el tranvía que, en su camino hacia Chorrillos, pasaban los campos de Santa Beatriz. Sin embargo, no era necesario acudir en persona a los campos deportivos para

11
11 
participar en la modernidad que protagonizaban ya que las revistas de la época muy pronto comenzaron a llevar comentarios de las competencias atléticas, las carreras de bicicletas y los partidos de fútbol que se realizaban ahí, así como fotos para ilustrar la descripción de los eventos. Al estudiar las revistas de comienzos del siglo XX, las carreras de caballos, primer deporte de origen inglés en el Perú y perteneciente a "la primera época de la historia del deporte" en el país (Basadre, Historia vol. X 65), gozaron de un lugar privilegiado en cuanto a comentarios e imágenes. Las carreras de caballos antecedían el auge del fútbol y otros deportes que se hicieron populares en los primeros años del siglo XX, pero la inauguración del hipódromo de Santa Beatriz en 1903 hizo que los caballos se convirtieran en un espectáculo público como nunca antes. Las carreras hípicas ofrecían a las revistas la posibilidad de reunir aspectos claves, como los orígenes ingleses de un espectáculo que había ampliado su público pero que seguía siendo el punto de encuentro de las élites locales, quienes -como afirma Flores Galindo- acudían al hipódromo los domingos después de asistir a misa (123).

La experiencia y la visibilidad de los eventos deportivos, sea en persona o mediante su frecuente representación en las revistas ilustradas, contribuían de forma importante a la construcción de una modernidad limeña. Para Muñoz Cabrejo, en la Lima de comienzos del siglo XX hay dos nociones que se asocian sobre todo con la modernidad: "la noción de progreso vinculado con el desarrollo material de la ciudad y el ideal cosmopolita" (46), y el deporte permitía que los dos conceptos se experimentaran en un solo momento. Frente a las condiciones de los concurridos callejones en los que vivía buena parte de la población de Lima, para quienes la privacidad era desconocida, los nuevos espacios públicos ofrecían la posibilidad de una suerte de anonimato: al asistir a un partido de fútbol o al hipódromo se podía ver y ser visto, formar parte de un espectáculo que incluía el público, que luego podía aparecer fotografiado en las revistas. Los nuevos escenarios deportivos constituían así puntos de encuentro entre personas con vidas muy distintas y la posterior representación de estas experiencias en revistas ilustradas daba una visión de un país que rompía con las tradicionales divisiones sociales y raciales, una suerte de comunidad imaginada que se elaboraba no tanto a través de la palabra impresa, como en el modelo que propone Anderson, sino mediante la imagen reproducida.

Tales consideraciones se pueden observar en la imagen que se reproduce en la página siguiente, del número 1073 de Variedades (22 de setiembre de 1928, 18-19). Además de confirmar el buen público en el campeonato escolar de atletismo y su carácter heterogéneo (excepto con respecto a género) es interesante notar la temprana combinación de capitalismo de mercado y evento deportivo mediante la propaganda de D'Onofrio y de un taller de escultura y marmolería en el recinto, así como la prominencia del salto a la garrocha que había figurado cincuenta años antes en El Perú Ilustrado.

Para Muñoz Cabrejo “A juicio de los modernizadores, la creación de nuevos lugares era propicia para desarrollar el nuevo estilo de vida citadino donde las formas

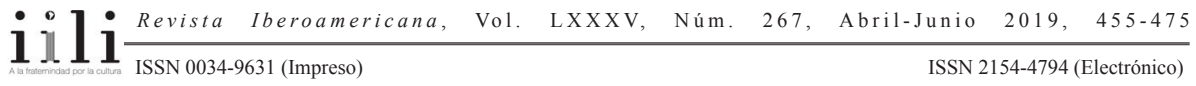




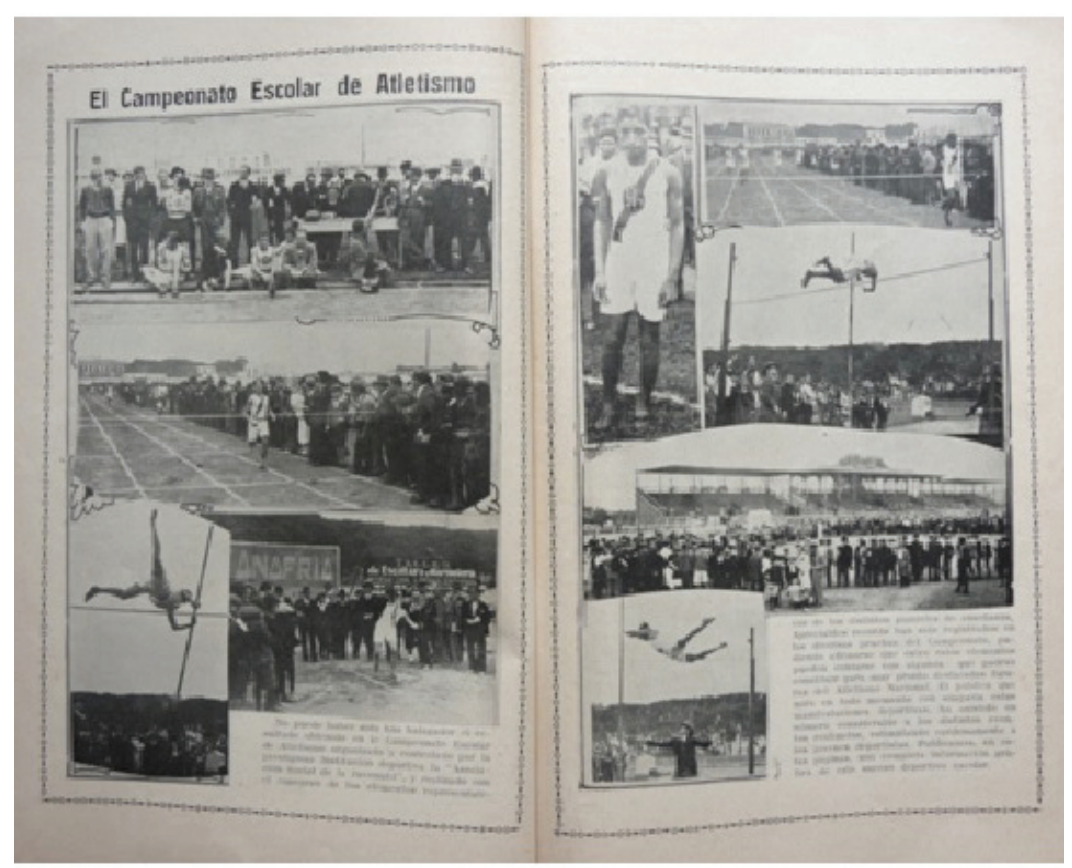

de sociabilidad caracterizadas por un universo más amplio se yuxtaponen a las antiguas, restringidas a espacios familiares pequeños" (52). Este universo más amplio puede aplicarse tanto al espacio físico de los estadios deportivos o del hipódromo como al espacio imaginario o representado de la práctica de estos deportes y sus orígenes británicos, todo supuestamente compartido por los que practicaban los deportes o frecuentaban como espectadores los estadios en los que se realizaban. Dentro de una ciudad y una sociedad donde seguían notándose marcados contrastes de vivienda e ingresos, y donde solo el cinco por ciento de la población tenía derecho al voto en la primera década del siglo XX (Elmore 17), el ámbito del deporte como espacio público abierto a una mirada multitudinaria se ofrecía como uno de los primeros ejemplos de una democratización temprana. Si la creación de nuevos espacios deportivos públicos significó para los sectores menos pudientes la oportunidad de alcanzar una suerte de simultáneo anonimato y protagonismo en eventos masivos, al mismo tiempo ofreció uno de los primeros puntos de acceso a las actividades sociales de las élites tradicionales. Las revistas ilustradas cumplían un rol primordial como mediadores de esta experiencia, haciendo que resultara visible a un público que se extendía mucho más allá del mismo estadio o hipódromo. Elmore reconoce el papel de las revistas ilustradas en cambiar la dinámica de las relaciones sociales de la época cuando afirma que: "Actualidades, Variedades o El Turf, entre otras publicaciones de la época, cumplían así el tácito

\begin{tabular}{l}
1110 \\
\hline ISSN 0034-9631 (Impreso)
\end{tabular} 
encargo de confirmar un orden en el que la vida privada -aunque, por supuesto, no la íntima- de la casta oligárquica se hacía, parcialmente, pública" (18). Lo que habría que añadir es que muchas veces esta casta oligárquica aparecía con personas de otras clases sociales en espacios deportivos, haciendo doblemente pública la participación de estas en la nueva modernidad.

La explosión en la última década del siglo XIX y las primeras del XX de la práctica sobre todo del fútbol y el atletismo, y los simultáneos avances tecnológicos con respecto a la fotografía y las máquinas de imprimir, se manifestaron en una serie de publicaciones que se dedicaban parcial o enteramente a los deportes. Es de notar que las primeras, El Toreo: semanario taurino (1888), La Reseña Taurina (1892) y El tiro al blanco: órgano de las sociedades de tiro al blanco y de esgrima en el Perú (1894), salieran poco después de figurar estos deportes en El Perú Ilustrado, y que tuvieran el formato de periódicos, sin una fuerte presencia de imágenes. Esta situación cambió en el umbral del nuevo siglo, y a partir del primer número de El Sport: Quincenario Ilustrado, Órgano de las Sociedades de Tiro (1899-1900) casi todas las publicaciones de la época hacían referencia explícita en su título a la dimensión visual de lo que pasaron a ser mayormente revistas. Otros ejemplos tempranos serían Sporty Variedades: Decenario Ilustrado de Sport, Letras, Ciencias y Amenidades (Lima, 1900); Prisma, Revista Social Ilustrada de Artes, Letras, Sport (Lima, 1905-1907); y Los Sports: Revista Semanal Informativa, Ilustrada e Independiente (Lima, 1916).

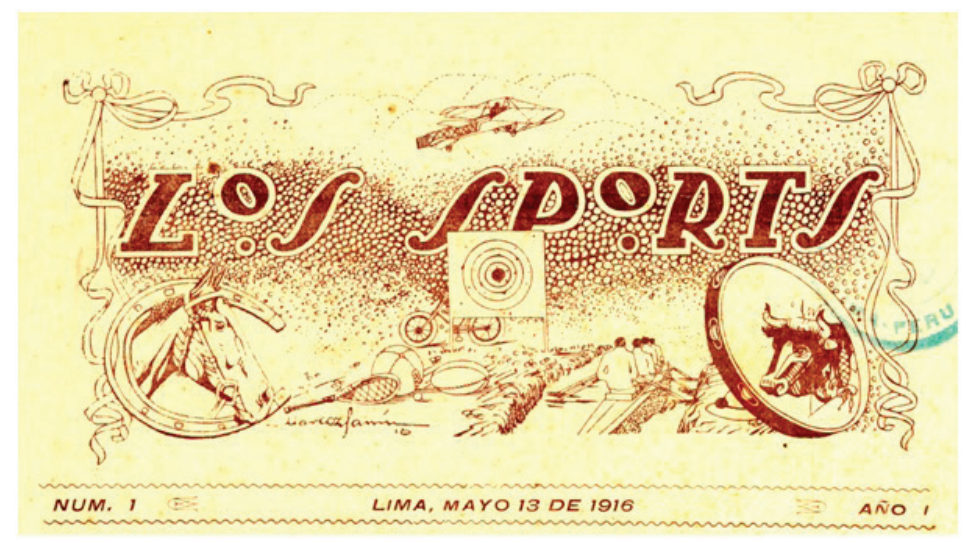

Como se puede apreciar de la parte superior de la carátula de Los Sports que se reproduce arriba, hay algunos puntos de comparación con los deportes que habían figurado en El Perú Ilustrado (el tiro al blanco, el tenis, los caballos y los toros) pero la bicicleta, el remo y el avión en particular ofrecen evidencia de la importación de nuevas tecnologías europeas. El avión sobre todo refleja la preocupación con la modernidad

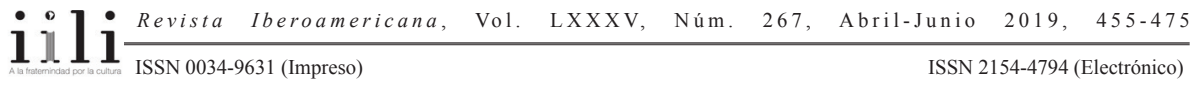


a través de la noción del progreso y el desarrollo: en enero de 1911, en un biplano que había traído desde Francia, Juan Bielovucic partió desde los campos de Santa Beatriz para realizar el primer vuelo en el Perú. Sin embargo, el avión en la imagen se parece más bien a un Bleriot como el que usó Jorge Chávez en su intento mortal de ser el primero en cruzar los Alpes en 1910, hazaña que realizaría con éxito Bielovucic en 1913. Al plasmar las experiencias de Bielovucic y Chávez en la imagen de un Bleriot que sobrevuela un contexto peruano, Los Sports celebra la posición de estos aviadores peruanos en la vanguardia continental y mundial de esta nueva tecnología (Bielovucic ya había conseguido varias marcas mundiales de tiempos de vuelo y altitud). Al mismo tiempo, al ubicar el avión encima del blanco que se usa en el tiro los deportes siguen haciendo eco de la derrota en la Guerra del Pacífico, cumpliendo un rol importante en la supuesta defensa del país: Bielovucic había dado las primeras clases de aviación a oficiales del ejército peruano después de su vuelo limeño en 1911, y había realizado numerosos vuelos como oficial peruano-francés durante los primeros años de la Primera Guerra Mundial, recibiendo medallas del Perú y de Bélgica por sus acciones.

El texto "Nuestro propósito", que afirma en el primer número de Los Sports la ideología de la nueva revista, describió el deporte como "esa práctica que ennoblece y dignifica, y que a la par que conserva sano el espíritu, robustece el cuerpo y sirve de factor muy importante al desarrollo intelectual" (13 de mayo de 1916, 1) para luego constatar que "se ha hecho fórmula corriente: Mens sana in corpore sano". La función que aquí se adscribe a los deportes parece haber cambiado poco del positivismo y darwinismo social que se notó en El Perú Ilustrado, lo cual se confirmó en el mismo texto editorial de Los Sports con "el muy justo pero oprobioso título de que: El Perú es un hombre enfermo" (13 de mayo de 1916, 2). Si bien la nación se concibe como una extensión del estado físico de sus pobladores, la solución para las revistas ilustradas deportivas radica en "la suprema necesidad de que en todo el Perú se practiquen los sports; que sirva de complemento la educación física a la intelectual; que nuestras masas ciudadanas se hagan ágiles, fuertes y poderosas" (13 de mayo de 1916, 2). Lo que sí ha cambiado es la participación de las "masas ciudadanas" en el deporte, hasta el punto en que: "Créese que el ejercicio del foot-ball y del cricket, por ejemplo, solo es dable a la gente proletaria, al pueblo y, a lo más, para servir de distracción a los colegiales: ¡triste error!” (2). Esta participación masiva se hacía notar todas las semanas en los informes e imágenes sobre eventos atléticos y campeonatos de fútbol y, a partir de la década de 1920, incluye a las mujeres como deportistas, sobre todo en natación, tenis y vóley (Wood, "Representing Peru”). En el siguiente número de Los Sports se informó que "El número de los clubs deportivos radicados en la Capital y sus alrededores llega a la muy halagadora cifra de 120" (20 de mayo de 1916, 1) y para abastecer al creciente número de personas que practicaban los deportes las mismas revistas llevaban avisos que anunciaban la venta de una serie de artículos deportivos importados. Dentro de la portada del primer número de Los Sports, por ejemplo, se

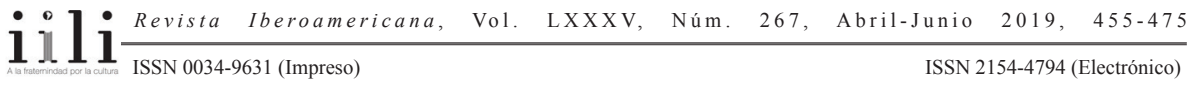


avisó: "Sportsmen. No olvidéis que la mejor casa/ proveedora de toda clase de útiles/ deportivos es la/ English Store"; por su parte la revista ilustrada Sport (17 de mayo de 1917) llevó en su primera página dos avisos: uno de Bazar Pathé que ofrecía "El mejor surtido de artículos de Sport / Foot Balls, Infladores, Canilleras / Racketas y pelotas para Tennis" que le permitía considerarse "Proveedor de los Primeros Clubs de Foot Ball de la República"; y otro de Otero y Cia "Importadores de artículos americanos" como "Rackets, Prensas, Pelotas y Zapatos para Lawn Tennis; Guantes y bats para el juego de Base-Ball; Guantes para Box; Bicicletas Columbia; Chompas de lana para ciclistas; Patines Wainslow; Jebes y resortes para ejercicios físicos; Repuestos para automobiles [sic] y bicicletas". Esta gama de deportes coincide precisamente con los que figuran en la portada de Los Sports que se reproduce arriba, aunque la exclusión de artículos para caballos o el toreo confirma la posición periférica de estas actividades tradicionales tanto en el imaginario nacional como en la construcción de la portada de una revista moderna. Mediante estas representaciones visuales y textos acompañantes se elaboró una serie de relaciones entre actividades deportivas que se habían introducido al país en la segunda mitad del siglo XIX o las primeras décadas del XX y bienes de consumo, importados de los mismos países que eran el punto de origen de los nuevos deportes modernos (Inglaterra, Francia, los Estados Unidos). El resultado, y quizás también el propósito, era confirmar la participación del país en el mercado internacional y afirmar la modernidad de un Perú cosmopolita donde el ámbito público -y deportivo- se hacía cada vez más visible.

Las revistas ilustradas dedicadas a los deportes gozaban muchas veces-como otras revistas ilustradas en el Perú- de una vida relativamente corta, pero la importancia que se prestaba al tema se nota en los numerosos intentos por fundar una serie de revistas especializadas en el deporte, así como la incorporación de los deportes en revistas ilustradas "de familia" (por ejemplo, El Perú Ilustrado, Actualidades o Variedades). Las primeras revistas ilustradas en el Perú eran de Lima, aunque el proceso de reconstrucción nacional después de la Guerra del Pacífico y el deseo de participar en la modernidad cosmopolita hicieron que tanto el Perú más ampliamente como los países que se encontraban en la vanguardia de la modernidad figuraran en ellas. Por otro lado, ya en 1914 se publicó en Arequipa la revista Sporting Club Arequipa y en 1926 El Sport: Semanario que Defiende los Intereses de los Clubs Sportivos de la Provincia se inauguró en Huacho, prueba de que ni la modernidad deportiva ni las revistas especializadas se limitaban a la capital.

En el contexto de su estudio de la modernidad en la literatura peruana Elmore afirma que "Uno de los contrastes claves que opone el mundo moderno al tradicional se sostiene en la presencia (casi podría corregirse, la omnipresencia) de la tecnología en las esferas de la producción y la vida cotidiana" (41). Esta fuerte presencia de la tecnología se manifestó igualmente en el deporte, la fotografía y las revistas ilustradas, prácticas y productos que experimentaron una expansión vertiginosa entre 1885 y

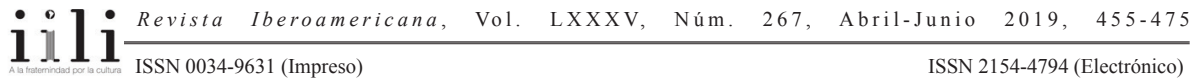


1930. En este mismo periodo las ideas “científicas" del positivismo europeo se vivían en Lima mediante una nueva infraestructura urbana para mejorar la salud pública, la construcción de nuevos barrios que rebasaban las antiguas murallas de la ciudad colonial y espacios públicos donde sectores cada vez más grandes de la población gozaban de nuevas actividades de ocio. Estas múltiples rupturas con la tradición implicaron el uso de nuevas tecnologías, nuevas ideas y nuevos comportamientos ejemplificados por los deportes que se importaron en este periodo de Inglaterra, Francia y los Estados Unidos. Al mismo tiempo, tales prácticas representan uno de los elementos más emblemáticos para la inserción de amplios sectores de la población en el discurso de la historia universal (occidental) y en los mercados internacionales de bienes de consumo. Igual que los deportes, las revistas ilustradas eran símbolo del uso de las últimas tecnologías importadas (la fotografía, las máquinas de imprimir, los avisos para aparatos domésticos) y de las ideas de la Ilustración secular.

A la luz de estas consideraciones, se puede concluir que en el periodo que hemos analizado los deportes y las revistas ilustradas participaban de un mismo impulso después de la catastrófica Guerra del Pacífico por romper con las tradiciones coloniales y buscar la forma de hacer que el país participara en la modernidad occidental. Para García Canclini, "La modernidad es [...] como una máscara. Un simulacro urdido por las élites y los aparatos estatales, sobre todo los que se ocupan del arte y la cultura" (20). En ciertos contextos esto podría ser cierto, pero, en el Perú de la época que hemos considerado aquí, la modernidad es una experiencia cotidiana para sectores cada vez más amplios de la población; se vive en carne y hueso con los deportes y de forma visual a través de las revistas ilustradas, que cumplen un importante rol mediador hacia un proyecto de (re-)construcción nacional. La creciente presencia en estas revistas de nuevos estadios y otros espacios públicos dedicados a las modernas prácticas deportivas es simbólica de nuevas formas de organizar la relación con el tiempo, tanto personal y cotidiano como nacional y universal. Por otro lado, la capacidad del cada vez mayor número de revistas dedicadas a los deportes de plasmar conceptos de la Ilustración europea con una visualización de la velocidad y la luz - en los espacios públicos y en la fotografía- hace que estas merezcan un lugar más destacado en los estudios de la modernidad periférica y latinoamericana. 
BiBLIOGRAFÍA

Anderson, Benedict. Imagined Communities. Reflections on the Origin and Spread of Nationalism. 1983. Londres: Verso, 1991.

Basadre Grohmann, Jorge. Historia de la República del Perú. Lima: Ediciones El Comercio, [s.f.].

La multitud, la ciudad y el campo. Lima: Editorial Huascarán, 1947.

Clarke, Graham. The Photograph. Oxford: Oxford UP, 1997.

Davies, Rhian. La España Moderna and Regeneración: A Cultural Reviewin Restoration Spain, 1889-1914. Manchester: Manchester Spanish and Portuguese Studies, 2000.

Dussel, Enrique. "Europe, Modernity, and Eurocentrism." Nepantla: Views from South 1/3 (2000): 465-78.

Elmore, Peter. Los muros invisibles. Lima y la modernidad en la novela del siglo XX. Lima: Mosca Azul / El Caballo Rojo ediciones, 1993.

Flores Galindo, Alberto. La agonía de Mariátegui: la polémica con la Komintern. Lima: DESCO, 1982.

García Canclini, Néstor. Culturas hibridas. Estrategias para entrar y salir de la modernidad. Mexico DF: Grijalbo, 1990.

Gargurevich Regal, Juan. "Del grabado a la fotografía. Las ilustraciones en el periodismo peruano". San Marcos (revista editada por el rectorado de la Universidad Nacional Mayor San Marcos) 24 (2006): 133-50.

Prensa, radio y TV. Historia crítica. Lima: Editorial Horizonte, 1987.

Hall, Stuart. "The Question of Cultural Identity". Modernity and its Futures. Stuart Hall, David Held y Tony McGrew, eds. Cambridge: Polity Press, 1992. 274-325. "Historia del Steeplechase". <www.steeplechasemuseum.org $>$.

"History of Bicycle Racing in Britain". <www.sixday.org.uk>.

Mariátegui, José Carlos. "La urbe y el campo". El Mundial. 3 oct. 1924. Citado en Hugo Cancino Troncoso. "Mariátegui y el proyecto de la modernidad". Revista Logos 12 (2002): 117-33.

Marien, Mary Warner. Photography: A Cultural History. Londres: Laurence King Publishing, 2002.

Maxwell, Anne. Colonial Photography and Exhibitions: Representations of the 'Native' and the Making of European Identities. Londres: Leicester UP, 1999.

McQuire, Scott. Visions of Modernity. Representation, Memory, Time and Space in the Age of the Camera. Londres: Sage, 1998.

Muñoz Cabrejo, Fanni. Diversiones públicas en Lima 1890-1920. La experiencia de la modernidad. Lima: Red para el desarrollo de las ciencias sociales en el Perú, 2001.

Núñez, Javier. "Signed with an X: Methodology and Data Sources for Analyzing the Evolution of Literacy in Latin America and the Caribbean, 1900-1950". Latin American Research Review 40/2 (June 2005): 117-35.

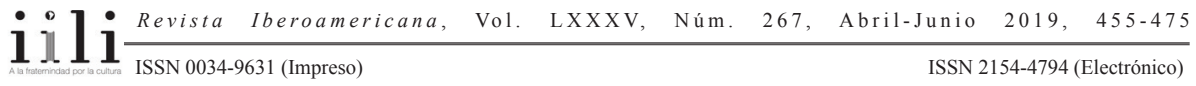


La Opinión Nacional. 15 junio 1887.

Panfichi, Aldo. "La urbanización de Lima, 1535-1900". <www.blog.pucp.edu.pe>. El Perú Ilustrado. <www.archive.org>.

Poole, Deborah. Vision, Race and Modernity: A Visual Economy of the Andean World. Princeton: Princeton UP, 1997.

Sarlo, Beatriz. Una modernidad periférica: Buenos Aires 1920 y 1930. Buenos Aires: Nueva Visión, 1988.

Sobrevilla, David y Pedro Belaúnde, eds. ¿Qué modernidad deseamos? El conflicto entre nuestra tradición y lo nuevo. Lima: Epígrafe, 1994.

Tauzin Castellanos, Isabelle. "La imagen en El Perú Ilustrado". Bulletin de l'Institut Français d'Etudes Andines (Lima) 32/1 (2003): 133-49.

Temple, Robert. The History of Harness Racing in New England. Sin lugar de publicación (Estados Unidos): Xlibris Corporation, 2010.

Wood, David. "Representing Peru: Seeing the Female Sporting Body". Journal of Latin American Cultural Studies 21/3 (2012): 417-36.

Palabras clave: deporte, cultura visual, espacios públicos, modernidad

Recibido: $\quad$ junio 2016

Aprobado: $\quad$ septiembre 2018 
